\title{
O efeito da intenção de reeleição sobre gastos em saúde: Uma análise com base no modelo de reputação política
}

\author{
LUCAS NOVAES* \\ ENLINSON MATTOS**
}

The effect of reelection intention on public health expenditures: An analysis based on reputation models. The political model of reputational-building argues that if the incumbent politician aspires to be reassigned, he/she must act in the voters' interest to obtain their approval and consequently their votes. Considering that voters are sensitive to public health expenditures, we check how reputational incentives shift municipal spending patterns in electoral years. The empirical tests for 3.004 Brazilian municipalities show an increase of health expenditures in those cities in which incumbents are trying to maintain their jobs. In addition, we find an increment in health expenditures where mayors forfeit their chance of being reelected to the benefit of a party mate.

Keywords: electoral control; reelection; political agency.

JEL Classification: D72; H51; H72; I18.

\section{INTRODUÇÃO}

Eleição é o principal instrumento de controle político em uma democracia. Candidatos devem convencer os eleitores sobre sua capacidade de governar e atender às expectativas. Por esse motivo, a possibilidade de recondução ao cargo tem papel decisivo na formulação de políticas públicas. Se o político extrai benefícios

\footnotetext{
* Doutorando - University of California, Berkeley, Travers Department of Political Science. E-mail: novaes@berkeley.edu.

* Escola de Economia de São Paulo da Fundação Getulio Vargas - EESP/FGV. E-mail: enlinson.mattos@fgv.br.

Os autores agradecem a George Avelino, Verônica Orellano, Kátia Saito e dois pareceristas anônimos por valiosas sugestões e comentários. Lucas Novaes agradece apoio financeiro da Capes. Erros remanescentes são de nossa inteira responsabilidade. Submetido: Novembro 2007: Aprovado: Agosto 2008.
} 
ao ocupar um cargo público, procurará maximizar a probabilidade de ser eleito. Caso o político pretenda manter sua função através da reeleição, ele tem incentivos para se alinhar às preferências do eleitorado, em detrimento de suas próprias.

O objetivo desse trabalho é analisar o efeito do esforço de prefeitos em adquirir uma reputação com eleitores durante a reeleição no contexto de gastos municipais na saúde em ano eleitoral. Analisamos o padrão municipal destes gastos nos anos eleitorais 2000 e 2004, os dois primeiros períodos eleitorais em que a emenda da reeleição esteve em vigor para municípios. Apesar de haver outras tentativas de se verificar ciclos eleitorais no Brasil, não encontramos nenhuma análise na literatura do tema a partir de amostra de municípios brasileiros.

A literatura sobre o problema de agência política é bastante extensa. Existem ao menos duas correntes teóricas que tentam explicar o papel das eleições no resultado da política pública. A primeira segue Rogoff e Silbert (1988) e Rogoff (1990), e foca em ciclos políticos orçamentários. Segundo essa linha, ciclos econômicos e ciclos eleitorais coincidem porque o governante, não importando partido ou ideologia, quer sinalizar ao eleitor que é um administrador eficiente. O ciclo orçamentário ocorre devido à assimetria de informação temporária sobre o tipo do governante. Como o eleitor não sabe exatamente o tipo do seu governante, este último é incentivado a aumentar gastos em itens mais visíveis e diminuir gastos em outros, como investimento.

Outra linha de pesquisa segue o modelo de reputação, inicialmente apresentado por Barro (1970), seguido por Banks e Sundaram (1993) e Besley e Case (1995). Em um mundo com informação imperfeita e agentes racionais, reeleição e final de mandato têm implicações em políticas públicas. Na presença de informação assimétrica entre o político e os eleitores, a reeleição pode funcionar como um mecanismo de repressão a ações oportunistas ou uma maneira de incentivar o esforço do político para criar ou manter uma relação com o eleitorado. Os eleitores percebem a capacidade do representante político em suprir bens públicos como medida de desempenho e sinalização sobre o tipo do político em exercício.

Estes modelos envolvem eleitores e governante em dois períodos. O governante escolhe o seu nível de esforço no primeiro período. Isso altera, em termos de probabilidade, a realização de determinada política pública, e, consequentemente, a utilidade dos eleitores, que está diretamente relacionada à provisão de bens públicos. No momento em que a política pública se realiza ou não, os eleitores podem tirar conclusões sobre o tipo do governante e, desta forma ao votar, estes eleitores aumentam ou reduzem as chances do atual governante de ser reeleito.

O governante que pode se reeleger deve pesar tanto a sua utilidade de curto prazo como uma possível utilidade no segundo mandato (sua utilidade é zero caso não esteja no poder). Se os eleitores são beneficiados pela distribuição de bens públicos, e estes dependem do esforço do governante, o político terá maiores chances de reeleição quanto mais se esforçar. Assim, a utilidade do político no segundo período depende fundamentalmente do seu desempenho no primeiro período ou, mais explicitamente, da sua reputação criada com o eleitorado através do seu es- 
forço em prover bens públicos. ${ }^{1}$ Portanto, o bem-estar deste político, no segundo período, está diretamente relacionada a execução da política pública visível e em acordo com os interesses dos eleitores no primeiro período. Já o político que não pode se reeleger escolhe o seu nível de esforço de modo maximizar sua utilidade no curto prazo.

Em termos empíricos, Besley e Case (1995) testam o comportamento de governadores dos Estados Unidos através desse modelo de reputação. Segundo os autores, diferenças no comportamento dos governadores que encaram o final do mandato em relação a aqueles que podem tentar a recondução se evidenciam na carga fiscal e despesas dos estados. No caso, estes autores identificam um ciclo eleitoral tributário entre os partidos Republicano e Democrata, ou seja, quando levados ao poder, de forma alternada, o primeiro partido (Republicano) imporia taxações mais brandas enquanto que o segundo (Democrata) executaria carga tributária mais expressiva.

List e Sturm (2006) mostram que mesmo em políticas secundárias, por exemplo o meio ambiente, o modelo de reputação também se aplica.

Já Veiga e Veiga (2007), utilizando o modelo de Rogoff (1990), examinam a existência de ciclos políticos em municípios portugueses. Resultados obtidos pelos autores corroboram a tese de que os prefeitos agem estrategicamente em períodos eleitorais, aumentando os gastos visíveis ao eleitorado.

Para o caso brasileiro, Meneguin e Bugarin (2001) argumentam que o governante tende a gastar mais quando não espera ser reeleito e a ser mais contido quando espera sucesso na reeleição. O teste empírico para estados brasileiros mostrou-se oposto ao previsto pelo modelo de ciclos eleitorais. $\mathrm{O}$ argumento utilizado para explicar esse fenômeno foi o de que a reeleição incentivaria os governantes a não se endividarem, pois se fossem reeleitos teriam que arcar com o peso do passivo. Nakaguma e Bender (2006) além de estudar o impacto da reeleição para estados testam o impacto da Lei de Responsabilidade Fiscal. Segundo esses autores, e ao contrário de Meneguin e Bugarin (2001), a reeleição propiciou ciclos políticos mais acentuados, estimulando manipulações oportunistas nos períodos de eleição. ${ }^{2}$

Os resultados sugerem que prefeitos candidatos à reeleição aumentam gastos na área examinada. Controlando por incentivos políticos, encontramos evidências de que prefeitos em primeiro mandato que não tentam reeleição também aumentam os gastos em saúde. Este comportamento, semelhante ao prefeito que tenta a reeleição, pode ocorrer porque o prefeito que não tenta a reeleição pode querer que

\footnotetext{
${ }^{1} \mathrm{O}$ principal resultado que se obtém nestes modelos é que caso sejam permitidos dois mandatos consecutivos, o governante que consegue alocar um nível de política pública razoável para a realização de utilidade do eleitorado no primeiro mandato, terá mais chances de se reeleger. Aqueles que estão no segundo mandato se esforçam menos, na média, do que aqueles em primeiro mandato.

${ }^{2}$ Ainda, Ferraz e Finan (2005) testam como incentivos à reeleição afetam o nível de extração de renda dos governantes. Usando uma amostra de municípios e dados de corrupção, os autores mostram que municípios com prefeitos no segundo mandato apresentam um maior nível de corrupção do que municípios de prefeitos em primeiro mandato.
} 
seu colega de partido seja seu sucessor. Por fim, encontramos que prefeitos em segundo mandato não parecem se esforçar para o sucesso eleitoral de seu partido.

$\mathrm{O}$ artigo contém outras três seções além desta. A seguir discutiremos o modelo de reputação e as hipóteses a serem testadas para o caso dos municípios brasileiros, além dos dados e particularidades sobre reeleição e saúde no Brasil. A terceira seção apresenta o modelo econométrico utilizado, os resultados das estimações e dos testes de hipóteses levantados na segunda seção. A última seção discute os resultados e conclui o trabalho.

\section{EFEITO DA REELEIÇÃO SOBRE GASTOS EM SAÚDE: O MODELO GERAL}

Levando em conta o modelo de reputação de Besley e Case (1995) tentamos identificar como a possibilidade de se reeleger ou não altera o gasto municipal em saúde. De acordo com o modelo, o governante que tenta reeleição deverá sinalizar competência aos possíveis eleitores em distribuir bens públicos. A hipótese desse trabalho é a de que ao elevar os gastos em saúde o governante estará se esforçando para prover bens públicos aos eleitores e, assim, construir uma reputação que aumente suas chances de se reeleger. Portanto, de acordo com este modelo, prefeitos que tentam reeleição aumentarão gastos em saúde. ${ }^{3}$

Partindo do pressuposto de que o eleitorado pode ser sensível aos gastos em saúde do governo, testamos como eventuais incentivos reputacionais podem alterar o padrão dessa rubrica nos municípios brasileiros. Neste sentido busca-se testar a hipótese de que prefeitos candidatos à reeleição gastam mais em saúde do que prefeitos que não concorrem à recondução ao cargo.

\section{Variações do modelo geral: prefeitos que não tentam a reeleição}

O prefeito em segundo mandato e o prefeito que não tenta reeleição, segundo o modelo de reputação, maximizará sua utilidade se perseguir uma agenda própria, não necessariamente alinhada aos eleitores. Então, para esses prefeitos, o modelo prevê que não haverá alteração significativa nos gastos, já que não há incentivos para se esforçar em criar uma reputação com eleitores.

Por outro lado, pode ser que os prefeitos em primeiro mandato, quando não concorrem à recondução do cargo, ajam de forma a construir reputação para que seu partido ocupe a cadeira de prefeito. Assim, observaríamos um aumento de gastos em saúde. Dessa forma, busca-se testar o caso em que o prefeito em primeiro mandato que não tenta a reeleição gasta mais em saúde para que o seu partido mantenha um colega de partido seu na prefeitura.

$\mathrm{O}$ mesmo argumento vale para prefeitos no segundo mandato. Isto implica testar a hipótese equivalente de que prefeitos em segundo mandato, por não estarem

\footnotetext{
${ }^{3}$ Ver Besley e Case (1995) para a formalização do modelo.
} 
possibilitados de concorrer, agem de maneira similar aos prefeitos que tentam a reeleição e também elevem os gastos em saúde.

\section{Variações no modelo geral: ideologia}

A ideologia do prefeito também pode influenciar o seu padrão de gastos durante o ano eleitoral. Afinal, um prefeito pode gastar mais em saúde por convicções próprias, reveladas pelo partido ao qual ele está filiado. Se, por exemplo, um prefeito de um partido de esquerda aumenta os gastos municipais em saúde não por causa das hipóteses reputacionais acima explicadas, mas por causa de sua ideologia, o modelo testado sofreria viés de variável omitida, e os resultados não serão válidos, pois o aumento de gastos não se dará devido a incentivos em solidificar uma reputação com eleitores.

Por esse motivo, realizamos teste econométrico onde cada prefeito foi classificado de acordo com sua ideologia.

\section{Variações no modelo geral: testando causalidade reversa}

Embora os resultados possam apontar a existência de incentivos reputacionais nas eleições municipais brasileiras, as estimações podem sofrer causalidade reversa. Ou seja, é possível que o prefeito tente reeleição por ter despendido um volume maior de verbas para a área da saúde, ao invés da hipótese desse trabalho, na qual o prefeito gasta mais em saúde porque tenta reeleição.

O teste consiste em eliminar da amostra prefeitos que de fato se reelegeram, parcela da amostra mais propensa a sofrer causalidade reversa. Assim, serão comparados prefeitos que perderam a reeleição com prefeitos em primeiro mandato que não tentaram a reeleição. Ao fazer isso, focamos a análise não nos resultados de se gastar mais em saúde, mas na opção do prefeito em separar parte dos recursos para sinalizar competência ao eleitorado.

Fonte de dados e tratamento das variáveis

A amostra compreende dois anos eleitorais: o ano 2000, que foi o primeiro ano em que prefeitos puderam se reeleger, e o ano de 2004. Para identificar os prefeitos que tentaram a reeleição no ano 2000, precisamos averiguar quais foram os prefeitos eleitos em 1996. Por esse motivo, a nossa amostra contém somente municípios existentes antes do ano de 1996. 
Gráfico 1: Período considerado e amostra utilizada

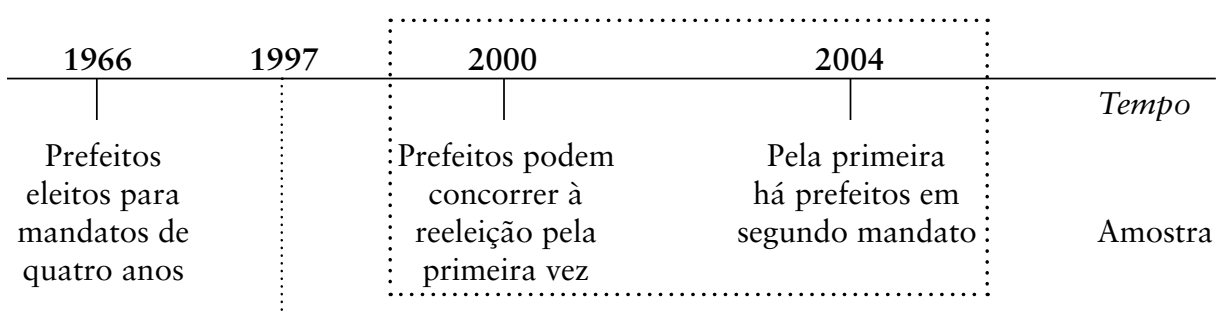

Reeleição é aprovada

Os dados eleitorais foram coletados no site do Tribunal Superior Eleitoral (TSE). ${ }^{4}$ Através da base de dados do TSE identificamos diferentes situações de prefeitos, que são: prefeitos que tentaram a reeleição, prefeitos que foram reeleitos, prefeitos em segundo mandato e prefeitos em primeiro mandato que não concorreram à reeleição. Também distinguimos entre os prefeitos que não tentaram reeleição se eles foram sucedidos por um colega de partido ou não, para então verificar se o comportamento desses prefeitos difere do grupo de referência, que é o prefeito em primeiro mandato que não tenta reeleição.

Gastos em saúde é nossa medida de política pública "visível” ao eleitorado. A escolha dessa variável deve-se em primeiro lugar pelo seu caráter imediato na função utilidade do eleitor e em segundo pela possibilidade de controlá-la por aspectos de saúde pública, como taxa de mortalidade e cobertura por planos de saúde, fatores além da demanda política. Além disso, podemos diferenciar quais gastos são originários na esfera municipal ou não. ${ }^{5}$

O sistema de saúde municipal apresenta alguns fatores peculiares. As gestões municipais podem ser caracterizadas ou pela Gestão Plena da Atenção Básica, ou pela Gestão Plena do Sistema Municipal. No primeiro caso, o município assume a responsabilidade sobre ações e serviços de atenção básica à saúde de sua população. A Gestão Plena indica que o município é responsável pela saúde dos munícipes em todos os níveis. Os municípios podem estabelecer convênios entre si, para aprovei-

\footnotetext{
${ }^{4}$ Cf. www.tse.gov.br.

${ }^{5} \mathrm{O}$ uso de saúde como variável dependente, ao invés de outro gasto possivelmente sensível ao eleitorado, como educação ou segurança pública, se justifica principalmente pela importância municipal na gestão da área. A descentralização da administração da saúde é uma das principais diretrizes do sistema. Além disso, é possível identificar quais gastos são originários de cada esfera de poder. Dessa maneira, podemos ao máximo limitar a análise à discricionariedade do político em questão, o prefeito. No caso da educação, a administração do ensino fundamental compete ao município enquanto ensino médio é visto como responsabilidade do governo dos estados. A separação das duas atribuições não é bem definida, e seria possível, por exemplo, municípios complementarem a educação primária com o financiamento destinado inicialmente ao ensino médio e vice-versa. Essa indefinição complicaria a análise proposta por esse trabalho, mas poderia ser executada em pesquisa futura. Segurança pública, por sua vez, é primordialmente competência do governo do estado, embora alguns municípios possuam guarda municipal.
} 
tar economias de escala em certos tratamentos. Dessa forma, se um município não tem recursos necessários para tratar certa enfermidade, o paciente pode ser transferido para outra localidade. Os custos do tratamento, entretanto, podem não ser completamente pagos pelo município de origem, o que pode levar a distorções nas despesas municipais (ver Teixeira et al., 2006) ${ }^{6}$.

A variável dependente, LNSAUDE, é o logaritmo do gasto municipal em saúde per capita, excluída as receitas advindas do Sistema Único de Saúde (SUS). Os dados para essa variável foram extraídos no Sistema de Orçamentos Públicos em Saúde (SIOPS), do Datasus/Ministério da Saúde.

As variáveis explicativas compreendem dummies para identificar prefeitos que tentam reeleição e prefeitos em segundo mandato. Além disso, identificamos prefeitos de primeiro mandato que não tentaram reeleição, mas foram seguidos por colega de partido e prefeitos em segundo mandato também seguidos por colega. Controlamos a regressão através de quatro classes de variáveis: controles políticos, controles relativos à área da saúde e controles municipais relativos à renda, demografia e saneamento.

Tabela 1: Descrição dos dados

\begin{tabular}{|c|c|c|c|c|c|}
\hline & $\begin{array}{l}\text { Todos os } \\
\text { prefeitos }\end{array}$ & $\begin{array}{l}\text { Prefeitos em } \\
\text { primeiro } \\
\text { mandato que } \\
\text { não concorrem } \\
\text { à reeleição }\end{array}$ & $\begin{array}{l}\text { Prefeitos que } \\
\text { concorrem à } \\
\text { Reeleição }\end{array}$ & $\begin{array}{l}\text { Prefeitos } \\
\text { que são } \\
\text { reeleitos }\end{array}$ & $\begin{array}{c}\text { Prefeitos } \\
\text { que estão } \\
\text { no segundo } \\
\text { mandato }\end{array}$ \\
\hline Número de obs. & 10963 & 3560 & 5490 & 3158 & 1913 \\
\hline \multirow{2}{*}{ Lnsaude } & 4.496 & 4.444 & 4.459 & 4.485 & 4.698 \\
\hline & [0.5313] & [0.5383] & [0.5337] & [0.5312] & [0.4593] \\
\hline \multirow{2}{*}{ Legislat } & 0.026 & 0.009 & 0.002 & - & 0.130 \\
\hline & [0.1602] & [0.0944] & [0.0405] & - & [0.336] \\
\hline \multirow{2}{*}{ Votmaj } & 0.726 & 0.694 & 0.713 & 0.761 & 0.824 \\
\hline & [0.4462] & {$[0.461]$} & [0.4524] & [0.4264] & [0.3806] \\
\hline \multirow{2}{*}{ Partpres } & 0.126 & 0.069 & 0.141 & 0.154 & 0.069 \\
\hline & [0.3319] & [0.2526] & [0.3484] & [0.3609] & [0.2526] \\
\hline \multirow{2}{*}{ Partgov } & 0.256 & 0.238 & 0.275 & 0.320 & 0.238 \\
\hline & [0.4365] & [0.4262] & [0.4467] & [0.4666] & [0.4262] \\
\hline \multirow{2}{*}{ Suplem } & 0.046 & 0.046 & 0.047 & 0.046 & 0.046 \\
\hline & [0.0839] & [0.0814] & [0.0841] & [0.0884] & [0.083] \\
\hline \multirow{2}{*}{ Lnmort } & 2.395 & 2.356 & 2.378 & 2.325 & 2.518 \\
\hline & [1.4298] & [1.4301] & [1.4345] & [1.4173] & [1.4113] \\
\hline
\end{tabular}

\footnotetext{
${ }^{6}$ Essa característica reforça necessidade de controlar a estimação econométrica por fatores estáticos não observáveis.
} 


\begin{tabular}{cccccc}
\hline Lnsus & 3.442 & 3.426 & 3.464 & 3.470 & 3.411 \\
& {$[0.5738]$} & {$[0.6029]$} & {$[0.568]$} & {$[0.5681]$} & {$[0.5307]$} \\
Lnpop & 9.366 & 9.321 & 9.385 & 9.330 & 9.394 \\
& {$[1.1239]$} & {$[1.1]$} & {$[1.1158]$} & {$[1.1457]$} & {$[1.1893]$} \\
Jovem & 0.198 & 0.196 & 0.199 & 0.198 & 0.200 \\
& {$[0.02]$} & {$[0.0205]$} & {$[0.0196]$} & {$[0.0201]$} & {$[0.02]$} \\
Popurb & 0.589 & 0.590 & 0.592 & 0.576 & 0.582 \\
& {$[0.2336]$} & {$[0.2311]$} & {$[0.2368]$} & {$[0.2407]$} & {$[0.2289]$} \\
Agua & 0.105 & 0.105 & 0.105 & 0.105 & 0.102 \\
& {$[0.0707]$} & {$[0.072]$} & {$[0.0711]$} & {$[0.0695]$} & {$[0.0674]$} \\
Esgoto & 0.050 & 0.046 & 0.050 & 0.054 & 0.053 \\
& {$[0.0512]$} & {$[0.0479]$} & {$[0.053]$} & {$[0.0561]$} & {$[0.0511]$} \\
Renda & 1.220 & 1.248 & 1.214 & 1.199 & 1.191 \\
& {$[0.7909]$} & {$[0.7675]$} & {$[0.7849]$} & {$[0.8066]$} & {$[0.8463]$} \\
\hline
\end{tabular}

Obs.: Desvio-padrão entre colchetes. Fontes: LNSAUDE, SUPLEM, LNMORT, LNSUS, AGUA e ESGOTO: DATASUS; LEGISLAT, VOTMAJ, PARTPRES, PARTGOV: TSE; LNPOP, JOVEM, POPURB e RENDA: Ipeadata.

Os controles políticos compreendem quatro variáveis. A primeira é LEGISLAT, uma dummy que mostra se o prefeito em exercício tentou cargo legislativo após o término do mandato. Através dessa variável podemos controlar casos onde o prefeito eventualmente planeje se candidatar a deputado ou senador, e por isso altere seus incentivos. VOTMAJ é uma dummy que indica se o prefeito foi eleito com uma margem de voto superior a $50 \%$. A inclusão dessa variável segue outros trabalhos, como Ferraz e Finan (2005) e List e Sturm (2006). PARTPRES e PARTGOV apontam se o prefeito é do mesmo partido do presidente ou governador, respectivamente. Uma vez que grande parte da receita municipal depende de repasses de outras esferas de poder, ${ }^{7}$ a relação partidária entre governantes pode interferir mo padrão de gastos municipais, inclusive gastos em saúde.

Ao todo, incluímos três controles da área da saúde. SUPLEM refere-se à razão da população municipal coberta por plano de saúde. ${ }^{8}$ A variável LNSUS é o logaritmo da transferência municipal per capita recebida através do SUS. LNMORT é a razão entre a quantidade de óbitos em $\log$ e o número de Autorizações de Internação Hospitalar (AIH) pagas, computadas como internações, no período, multiplicada por 100, por local de residência do paciente. Através dessa variável podemos controlar eventuais características municipais, como violência ou doenças endêmi-

\footnotetext{
${ }^{7}$ As receitas do SUS no ano de 2000 chegaram a 50,78\% das despesas totais de saúde nos municípios. Em 2004, a proporção foi de $45,78 \%$.

${ }^{8}$ A comparação entre as regiões do país mostra que a taxa de cobertura é bastante desigual. Por exemplo, o estado de São Paulo tem cerca de $38 \%$ da sua população coberta, enquanto Roraima somente $2 \%$ da população tem plano de saúde privado (fonte: Ipeadata). Porém, não necessariamente um maior número de pessoas com plano de saúde resulta em menores gastos públicos. Nishikima et al. (2006) argumenta que parte dos serviços médicos de pessoas com planos de saúde, principalmente os de alta complexidade, são custeados pelo governo.
} 
cas, que podem influenciar os gastos de saúde nos anos de estudo As variáveis de controle do setor de saúde foram extraídas do DATASUS/Ministério da Saúde. ${ }^{9}$

LNPOP, JOVEM e POPURB referem-se ao logaritmo da população municipal, à proporção de jovens na população entre 15 e 25 anos e à proporção da população urbana. RENDA refere-se ao logaritmo da renda per capita municipal. A inclusão desses controles segue a literatura (Besley e Case, 1995; Finan e Ferraz, 2005; List e Sturm, 2006). A variável AGUA informa a porcentagem de domićlios sem água encanada, enquanto ESGOTO mostra a proporção de domicílios sem rede própria de esgoto. A utilização dessas duas variáveis tem como objetivo controlar os gastos de saúde para possíveis diferenças fitossanitárias causadoras de doenças.

Os dados financeiros foram devidamente deflacionados com o uso da série histórica do IPCA.

A Tabela 1 mostra as diferenças nas características médias para o total de municípios e quatro outras situações a respeito do ambiente eleitoral. Como podemos observar, as variações são pequenas na maioria das variáveis e entre municípios com diferentes situações eleitorais.

\section{MODELO ECONOMÉTRICO}

\section{Modelo geral}

O objetivo da análise econométrica é tentar verificar como incentivos à reeleição afetam os gastos em saúde. A especificação econométrica utilizada para a análise foi:

$$
\text { Lnsaude }_{i t}=\zeta_{i}+\beta \text { eleicao }_{i t}+\psi P_{i t}+\varphi Z_{i t}+\lambda C_{i t}+\mu_{i t}
$$

A variável dependente, Lnsaude $_{i j}$, é o log do gasto municipal em saúde per capita no município $i$ e período $t$. $\zeta_{i}$ são características não observadas constantes no tempo para o município $i$. O vetor $\beta$ são os coeficientes das variáveis binárias eleitorais de interesse. Essas variáveis descrevem a situação eleitoral do prefeito no município $i$ no ano eleitoral. Ou seja, dependendo da especificação, eleicao descreve se o prefeito em primeiro mandato tenta ou não a reeleição, se o prefeito está em segundo mandato, ou se o prefeito em primeiro mandato que não tentou reeleição foi seguido por um colega de partido. $P_{i t}$ é o vetor de controles políticos (LEGISLAT, VOTMAJ, PARTPRES e PARTGOV), $Z_{i t}$ é o vetor de controles de saúde (SUPLEM, LNSUS e MORT), $\mathrm{C}_{\mathrm{it}}$ é o vetor de controles municipais (LNPOP, JOVEM, POPURB, RENDA, AGUA e ESGOTO). $\mu_{i t}$ é o resíduo.

Os dados compreendem dois períodos, 2000 e 2004. Por isso, podemos testar ao menos quatro diferentes especificações econométricas: Pooled OLS, painel de

\footnotetext{
${ }^{9}$ Cf. w3.datasus.gov.br/datasus/datasus.php.
} 
efeito aleatório, painel de efeito fixo e primeira diferença. Os resultados estão reportados na Tabela 2.

Tabela 2: Modelos estimados

\begin{tabular}{|c|c|c|c|c|}
\hline \multicolumn{5}{|c|}{ Variável dependente: LNSAUDE } \\
\hline & Efeito fixo & $\begin{array}{l}\text { Primeira } \\
\text { diferença }\end{array}$ & $\begin{array}{c}\text { Efeito } \\
\text { aleatório }\end{array}$ & $\begin{array}{l}\text { Pooled } \\
\text { OLS }\end{array}$ \\
\hline \multirow{3}{*}{$\begin{array}{l}\text { Prefeitos que } \\
\text { tentaram reeleição }\end{array}$} & 0.0670 & 0.0670 & 0.0523 & 0.0467 \\
\hline & {$[0.0278]$} & [0.0258] & {$[0.0179]$} & [0.0182] \\
\hline & $(0.016)$ & $(0.009)$ & $(0.003)$ & $(0.01)$ \\
\hline \multirow{3}{*}{$\begin{array}{l}\text { Prefeitos em segundo } \\
\text { wmandato }\end{array}$} & 0.0556 & 0.0556 & 0.0677 & 0.0704 \\
\hline & {$[0.0461]$} & {$[0.0426]$} & [0.0191] & [0.0188] \\
\hline & $(0.227)$ & $(0.192)$ & (0) & (0) \\
\hline \multirow{3}{*}{ Legislativo } & -0.0214 & -0.0214 & 0.0491 & 0.0618 \\
\hline & [0.0598] & [0.0553] & {$[0.0406]$} & [0.0419] \\
\hline & $(0.721)$ & (0.699) & $(0.226)$ & $(0.141)$ \\
\hline \multirow{3}{*}{ Votmaj } & 0.0344 & 0.0344 & 0.0512 & 0.0550 \\
\hline & [0.0257] & [0.0238] & {$[0.0175]$} & [0.0178] \\
\hline & $(0.181)$ & $(0.148)$ & $(0.003)$ & $(0.002)$ \\
\hline \multirow{3}{*}{ Partpres } & 0.0499 & 0.0499 & 0.0310 & 0.0256 \\
\hline & {$[0.0285]$} & [0.0264] & [0.0234] & [0.0245] \\
\hline & $(0.08)$ & (0.058) & $(0.186)$ & $(0.297)$ \\
\hline \multirow{3}{*}{ Partgov } & -0.0283 & -0.0283 & -0.0122 & -0.0089 \\
\hline & [0.0242] & [0.0224] & [0.0164] & [0.0167] \\
\hline & $(0.242)$ & $(0.206)$ & $(0.458)$ & (0.595) \\
\hline \multirow{3}{*}{ Suplem } & 0.0401 & 0.0401 & 1.5989 & 1.5962 \\
\hline & [0.3327] & [0.3078] & [0.1886] & [0.1813] \\
\hline & (0.904) & $(0.896)$ & (0) & (0) \\
\hline \multirow{3}{*}{ Lnsus } & -0.4225 & -0.4225 & -0.1179 & -0.0690 \\
\hline & [0.0317] & [0.0294] & [0.0175] & [0.0172] \\
\hline & (0) & (0) & (0) & (0) \\
\hline \multirow{3}{*}{ Mortalidade } & -0.0098 & -0.0098 & 0.0305 & 0.0355 \\
\hline & [0.0114] & [0.0106] & [0.0061] & [0.0061] \\
\hline & (0.391) & (0.354) & (0) & (0) \\
\hline \multirow{3}{*}{ Agua } & 1.7334 & 1.7334 & 0.1071 & 0.0299 \\
\hline & [1.7669] & [1.6349] & [0.1296] & [0.1181] \\
\hline & $(0.327)$ & (0.289) & $(0.409)$ & (0.8) \\
\hline \multirow{3}{*}{ Esgoto } & 0.8682 & 0.8682 & 1.0272 & 1.0370 \\
\hline & [0.5305] & [0.4908] & [0.2424] & [0.2305] \\
\hline & $(0.102)$ & $(0.077)$ & (0) & (0) \\
\hline \multirow{3}{*}{ Renda } & 0.2193 & 0.2193 & 0.3759 & 0.3804 \\
\hline & [0.0491] & [0.0455] & {$[0.0148]$} & [0.0141] \\
\hline & (0) & (0) & (0) & (0) \\
\hline
\end{tabular}




\begin{tabular}{lcccc}
\hline & -0.6203 & -0.6203 & -0.3556 & -0.3592 \\
População & {$[0.2598]$} & {$[0.2404]$} & {$[0.0116]$} & {$[0.0109]$} \\
& $(0.017)$ & $(0.01)$ & $(0)$ & $(0)$ \\
Urban & -0.0487 & -0.0487 & -0.0199 & -0.0120 \\
& {$[0.0531]$} & {$[0.0491]$} & {$[0.0329]$} & {$[0.0336]$} \\
& $(0.359)$ & $(0.322)$ & $(0.545)$ & $(0.721)$ \\
Jovens & 6.8663 & 6.8663 & 2.2559 & 2.3112 \\
& {$[4.8642]$} & {$[4.5006]$} & {$[0.6118]$} & {$[0.5598]$} \\
N. obs & $(0.158)$ & $(0.127)$ & $(0)$ & $(0)$ \\
Prob > F,W & 7018 & 3004 & 7018 & 7018 \\
R2 & 0.0000 & 0.0000 & 0.0000 & 0.0000 \\
\hline
\end{tabular}

Obs.: Erro-padrão robusto entre colchetes e p-valor entre parênteses. Todas as estimações incluem intercepto e dummy de ano. Para as estimações de efeito aleatório e Pooled OLS foram incluídas dummies para Unidades de federação.

O principal critério de seleção entre as especificações é a consistência dos estimadores. Dada a hipótese de exogeneidade estrita, $E\left(u_{i} \mid \mathrm{X}_{i t}\right)=0, \forall t=1,2$, as estimações em efeito fixo e primeira diferença são consistentes. Efeito aleatório e Pooled OLS serão consistentes somente se as características não observadas constante no tempo dos municípios não estiverem correlacionadas com as variáveis explicativas, isto é, $E\left(\varsigma_{i} \mid X_{i}\right)=E\left(\varsigma_{i}\right)=0$. Para testar a validade dessa hipótese, lançamos mão do teste de Hausman ${ }^{10}$ entre uma estimação consistente, a de efeito fixo, e outra possivelmente mais eficiente, efeito aleatório. O teste rejeita a hipótese nula de que a estimação efeito aleatório é consistente. ${ }^{11}$ Executamos o mesmo teste para o modelo Pooled OLS, e como poderíamos esperar a hipótese nula de consistência também tem que ser rejeitada. ${ }^{12}$

A escolha entre estimação de efeito fixo e primeira diferença é uma questão de eficiência do modelo. Pode ser mostrado que para $T=2$ as estimações reportam coeficientes idênticos, e sob hipótese de erros esféricos, a inferência também é igual. Porém, o teste LM Breusch-Pagan dos resíduos rejeita a hipótese de homocedasticidade. ${ }^{13}$ Com a necessidade de aplicar a matriz de erro robusta, a escolha recairá na presença ou não de autocorrelação. A estimação em primeira diferença para dois períodos apresenta uma matriz de variância e covariância matriz diagonal, o que descarta a possibilidade de autocorrelação. Por isso, adota-se o método de primeira diferença em todas as estimações subsequentes no trabalho.

Contudo, o exame das quatro estimações pode ilustrar a robustez do modelo.

\footnotetext{
${ }^{10}$ Ver Wooldridge, 2002, p. 288.

${ }^{11}$ A estatística $\chi^{2}(15)$ é 231,98, o que por sua vez traz o p-valor=0,0000.

${ }^{12}$ A estatística $\chi^{2}(15)$ para o modelo Pooled OLS é 295,47, e o p-valor=0,0000.

${ }^{13}$ A estatística $\chi^{2}(1)$ para o teste é de 199,59, o que nos dá um p-valor-0,0000 rejeitando a hipótese de homocedasticidade.
} 
Em comparação ao grupo de referência - municípios com prefeitos em primeiro mandato que não tentaram reeleição -, o coeficiente para o caso do município em que o prefeito tenta a reeleição é positivo e significante, enquanto o coeficiente para prefeitos em segundo mandato é insignificante. Estes resultados corroboram as hipóteses levantadas sobre modelo de reputação.

Com base na estimação em primeira diferença, podemos observar que, dos controles políticos, somente o fato do prefeito pertencer ao mesmo partido do presidente influi significativamente sobre os gastos em saúde. Visto que a maioria dos recursos em saúde se origina no plano federal, essa variável pode indicar que o relacionamento entre prefeito e presidente de um mesmo partido gera maiores gastos em saúde, seja através de favorecimento político ou de maior coordenação entre as duas esferas.

A proporção populacional atendida por plano de saúde privado não apresenta significância, assim como a taxa de mortalidade. Todavia, LNSUS mostra-se um importante determinante dos gastos em saúde. Quanto maior o repasse concedido pelo SUS ao município, menor a despesa municipal na área da saúde. Dos controles municipais, somente a renda per capita e população influem (positivamente) no gasto municipal. Portanto, quanto maior a renda da população, maior será o gasto do prefeito em saúde, e ao mesmo tempo, quanto maior o número de habitantes no município, maior a quantidade per capita de recursos repassados para a área da saúde.

\section{Testando o componente o político}

Apesar dos resultados das estimações anteriores aceitarem as hipóteses do modelo de reputação, podemos testar se incentivos partidários também importam na provisão de bens públicos na época de eleição.

O sistema político de incentivos pode funcionar de tal forma que o prefeito no segundo mandato, ou aquele que não tenta a reeleição, gaste mais em saúde para que o candidato de seu partido seja eleito. Seria uma modalidade diferente de reeleição. Se o político apoia o seu partido, o período pós-governo entra na sua função utilidade. Portanto, o prefeito em segundo mandato, ou o prefeito em primeiro mandato, pode ter incentivos análogos ao prefeito candidato à reeleição.

As estimações da Tabela 3 mostram os coeficientes de quatro diferentes situações: prefeito que tenta reeleição, prefeito em segundo mandato - tanto aquele sucedido por colega de partido ou não, e prefeito em primeiro mandato sucedido pelo colega de partido. Além disso, subdividimos a amostra de acordo com o tamanho do município. 
Tabela 3: Estimações com componente partidário

\begin{tabular}{|c|c|c|c|c|c|}
\hline \multicolumn{6}{|c|}{ Variável dependente: LNSAUDE } \\
\hline & $\begin{array}{l}\text { Todos os } \\
\text { Municípios }\end{array}$ & $\begin{array}{c}\text { Municípios } \\
\text { com população } \\
\text { superior à média } \\
\text { (31.425 } \\
\text { habitantes) }\end{array}$ & $\begin{array}{c}\text { Municípios } \\
\text { com população } \\
\text { inferior à média } \\
\text { (31.425 } \\
\text { habitantes) }\end{array}$ & $\begin{array}{c}\text { Municípios } \\
\text { com população } \\
\text { superior à me- } \\
\text { diana (11.960 } \\
\text { habitantes) }\end{array}$ & $\begin{array}{l}\text { Municípios } \\
\text { com população } \\
\text { inferior à me- } \\
\text { diana (11.960 } \\
\text { habitantes) }\end{array}$ \\
\hline \multirow{3}{*}{$\begin{array}{l}\text { Prefeitos que } \\
\text { tentaram } \\
\text { reeleição }\end{array}$} & 0.0756 & 0.1641 & 0.058 & 0.0827 & 0.0633 \\
\hline & [0.0254] & [0.0661] & [0.0276] & [0.039] & [0.0321] \\
\hline & (0.003) & (0.013) & (0.036) & $(0.034)$ & (0.048) \\
\hline \multirow{3}{*}{$\begin{array}{l}\text { Prefeitos em } \\
\text { segundo man- } \\
\text { dato que não } \\
\text { foram sucedi- } \\
\text { dos por colega } \\
\text { de partido }\end{array}$} & 0.0457 & 0.1729 & 0.0155 & 0.0857 & 0.0204 \\
\hline & [0.0429] & [0.115] & [0.046] & [0.0674] & [0.0533] \\
\hline & $(0.287)$ & (0.133) & (0.736) & $(0.204)$ & $(0.702)$ \\
\hline \multirow{3}{*}{$\begin{array}{l}\text { Prefeitos em } \\
\text { segundo man- } \\
\text { dato que foram } \\
\text { sucedidos } \\
\text { por colega de } \\
\text { partido }\end{array}$} & 0.0685 & 0.1503 & 0.0407 & 0.0414 & 0.0835 \\
\hline & [0.0532] & {$[0.1136]$} & {$[0.0597]$} & {$[0.0711]$} & {$[0.0792]$} \\
\hline & (0.198) & $(0.186)$ & (0.496) & $(0.561)$ & $(0.292)$ \\
\hline \multirow{3}{*}{$\begin{array}{l}\text { Prefeitos } \\
\text { em primeiro } \\
\text { mandato que } \\
\text { não tentaram } \\
\text { reeleição e } \\
\text { foram seguidos } \\
\text { por colega de } \\
\text { partido }\end{array}$} & 0.1245 & 0.4287 & 0.0798 & 0.2286 & 0.0483 \\
\hline & [0.046] & [0.1705] & [0.0468] & [0.0767] & [0.0552] \\
\hline & $(0.007)$ & $(0.012)$ & (0.088) & (0.003) & $(0.381)$ \\
\hline $\begin{array}{l}\text { Controles } \\
\text { políticos }\end{array}$ & Sim & Sim & Sim & Sim & Sim \\
\hline $\begin{array}{l}\text { Controles } \\
\text { saúde }\end{array}$ & Sim & Sim & Sim & Sim & Sim \\
\hline $\begin{array}{l}\text { Controles } \\
\text { município }\end{array}$ & Sim & Sim & Sim & Sim & Sim \\
\hline N. obs & 3004 & 507 & 2496 & 1503 & 1502 \\
\hline Prob $>F$ & 0.0000 & 0.0000 & 0.0000 & 0.0000 & 0.0000 \\
\hline R2 & 0.09 & 0.1472 & 0.0894 & 0.1189 & 0.0837 \\
\hline
\end{tabular}

Obs.: Todas as estimações em primeira diferença. Erro padrão robusto entre colchetes e p-valor entre parênteses. Todas as estimações incluem intercepto e dummy de ano. Controles políticos: LEGISLAT, VOTMAJ, PARTPRES e PARTGOV. Controles saúde: SUPLEM, LNSUS, MORT. Controles Município: AGUA, ESGOTO, RENDA, POPULAÇÃO, URBAN, JOVENS. 
O comportamento do prefeito em primeiro mandato segue a hipótese levantada e resultados anteriores. De fato, esses prefeitos gastam mais em saúde na situação em que é sucedido por um colega de partido. Embora o gasto em saúde seja uma medida imperfeita para o esforço desse prefeito para eleger o colega, uma vez que outros na mesma situação podem ter tentado eleger um colega e falhado, os resultados sugerem que de fato o componente político é relevante para o comportamento do prefeito.

Entretanto, esse efeito não é observado no prefeito de segundo mandato. Após o exercício de seu segundo termo, prefeitos não parecem se esforçar para a sucessão partidária dentro do seu município, ao menos não com gastos em saúde.

Os cortes populacionais mostram que os resultados, em geral, se mantêm. Seja qual for o tamanho do município, prefeitos que tentam reeleição efetivamente gastam mais em saúde. O coeficiente se mantém próximo à estimação com amostra completa, a não ser no caso dos municípios com população superior à média, onde o coeficiente aumenta de forma acentuada. Esse incremento também pode ser observado para o prefeito em primeiro mandato sucedido por colega. Somente em um caso resultados anteriores perdem significância. Prefeitos em primeiro mandato que não tentaram reeleição, mas foram seguidos por colega de partido aparentemente não gastam mais em saúde em municípios cuja população é inferior à mediana. Pode-se especular que em municípios menores o capital político é mais personalista, o que por sua vez diminui a importância de vinculações partidárias. Se essa hipótese for verdadeira, o empenho de prefeitos que não tentam a reeleição para eleger seu colega pode ser em vão.

\section{Testando ideologia}

O objetivo dessa seção é verificar se a ideologia partidária do prefeito é um controle relevante para explicar o padrão de gastos em saúde em ano eleitoral. Caso seja relevante, os resultados anteriores estariam com viés causado por variável omitida.

A classificação ideológica é baseada no partido do prefeito, conforme proposto por Coppedge (1997). Desta forma, o prefeito pode se enquadrar em cinco diferentes classificações do espectro ideológico: direita, centro-direita, centro, centro-esquerda e esquerda (coluna [1], Tabela 4). Em uma estimação alternativa, reunimos centro direita e direita em um único grupo, e de modo análogo, centro-esquerda e esquerda (coluna [2], Tabela 4).

A Tabela 4 informa os resultados dessas estimações. Conforme podemos observar, nenhuma denominação ideológica é significante para os gastos em saúde em anos eleitorais. Além disso, os coeficientes para as variáveis eleitorais se mantêm praticamente inalterados em comparação aos resultados obtidos na primeira coluna da Tabela 3. Ou seja, ideologia não parece configurar importante aspecto para a determinação dos gastos em saúde, e mais especificamente, não sugere alterações nos coeficientes das variáveis políticas. 
Tabela 4: Ideologia do prefeito

\begin{tabular}{|c|c|c|}
\hline \multicolumn{3}{|c|}{ Variável dependente: LNSAUDE } \\
\hline & [1] & [2] \\
\hline \multirow{3}{*}{ Prefeitos que tentaram reeleição } & 0.0763 & 0.0768 \\
\hline & {$[0.0256]$} & [0.0255] \\
\hline & (0.003) & (0.003) \\
\hline \multirow{3}{*}{$\begin{array}{l}\text { Prefeitos em segundo mandato que } \\
\text { não foram sucedidos por colega de } \\
\text { partido }\end{array}$} & 0.0472 & 0.047 \\
\hline & [0.043] & [0.043] \\
\hline & (0.273) & (0.275) \\
\hline \multirow{3}{*}{$\begin{array}{l}\text { Prefeitos em segundo mandato } \\
\text { que foram sucedidos por colega de } \\
\text { partido }\end{array}$} & 0.0651 & 0.0659 \\
\hline & [0.0535] & [0.0534] \\
\hline & (0.223) & (0.217) \\
\hline \multirow{3}{*}{$\begin{array}{l}\text { Prefeitos em primeiro mandato } \\
\text { que não tentaram reeleição e foram } \\
\text { seguidos por colega de partido }\end{array}$} & 0.1232 & 0.1243 \\
\hline & {$[0.0461]$} & [0.0459] \\
\hline & (0.008) & (0.007) \\
\hline \multirow{3}{*}{ Direita } & 0.0367 & 0.0364 \\
\hline & {$[0.0278]$} & [0.0247] \\
\hline & $(0.187)$ & $(0.141)$ \\
\hline \multirow{3}{*}{ Centro-direita } & 0.0352 & \\
\hline & {$[0.0364]$} & - \\
\hline & (0.334) & \\
\hline \multirow{3}{*}{ Centro-esquerda } & 0.0192 & \\
\hline & {$[0.0306]$} & - \\
\hline & $(0.53)$ & \\
\hline \multirow{3}{*}{ Esquerda } & -0.0040 & 0.0172 \\
\hline & {$[0.0628]$} & [0.0302] \\
\hline & $(0.949)$ & (0.568) \\
\hline Controles políticos & Sim & Sim \\
\hline
\end{tabular}




\begin{tabular}{lcc}
\hline Controles saúde & Sim & Sim \\
Controles município & Sim & Sim \\
\hline N. obs & 3004 & 3004 \\
Prob $>$ F & 0.0000 & 0.0000 \\
R2 & 0.0947 & 0.0946 \\
\hline
\end{tabular}

Obs.: Todas as estimações em primeira diferença. Erro-padrão robusto entre colchetes e p-valor entre parênteses. Todas as estimações incluem intercepto e dummy de ano. Controles políticos: LEGISLAT, VOTMAJ, PARTPRES e PARTGOV. Controles saúde: SuPLEM, LNSUS, MORT. Controles Município: AGUA, ESGOTO, RENDA, POPULAÇÃO, URBAN, JOVENS.

\section{Testando a causalidade reversa}

O objetivo das estimações desta seção é comparar municípios semelhantes, tentando eliminar situações de simultaneidade. No sentido de delimitar os efeitos do ciclo eleitoral para os gastos em saúde e não o contrário, elaboramos testes de robustez para os casos em que o componente reputacional esteve presente nas estimações anteriores: prefeitos em primeiro mandato e prefeitos em primeiro mandato seguidos por colegas de partido.

A comparação é feita somente em municípios com prefeitos exercendo o primeiro mandato. Além disso, eliminamos da amostra prefeitos que conseguiram se reeleger.

Tabela 5: Análise de robustez: somente prefeitos em primeiro mandato

\begin{tabular}{lcc}
\hline & \multicolumn{2}{c}{ Variável dependente: LNSAUDE } \\
\hline & $\begin{array}{l}\text { Amostra somente com } \\
\text { municípios ou com prefeitos } \\
\text { que tentaram a reeleição e } \\
\text { perderam ou prefeitos em } \\
\text { primeiro mandato não sucedidos } \\
\text { por colegas de partido }\end{array}$ & $\begin{array}{l}\text { Amostra somente com } \\
\text { municípios com prefeitos } \\
\text { que tentaram a reeleição e } \\
\text { perderam e prefeitos em } \\
\text { primeiro mandato seguidos } \\
\text { por colegas de partido }\end{array}$ \\
\hline Prefeitos que tentaram & 0.0696 & -0.1653 \\
reeleição e perderam & {$[0.0373]$} & {$[0.0813]$} \\
Controles políticos & $(0.063)$ & $(0.043)$ \\
Controles saúde & Sim & Sim \\
Controles município & Sim & Sim \\
\hline N. obs & Sim & 309 \\
Prob $>$ F & 964 & 0.0000 \\
R2 & 0.0000 & 0.1226 \\
\hline
\end{tabular}

Obs.: Todas as estimações em primeira diferença. Erro-padrão robusto entre colchetes e p-valor entre parênteses. Todas as estimações incluem intercepto e dummy de ano. Controles políticos: LEGISLAT, VOTMAJ, PARTPRES e PARTGOV. Controles saúde: SUPLEM, LNSUS, MORT. Controles Município: AGUA, ESGOTO, RENDA, POPULAÇÃO, URBAN, JOVENS. 
Como podemos observar na primeira coluna da Tabela 5, mesmo os prefeitos que não conseguiram se reeleger gastam mais em saúde do que prefeitos em primeiro mandato que não tentaram a reeleição e não tiveram colega eleito. Esse resultado sugere que prefeitos que tentam reeleição destinam maiores recursos para a saúde em comparação com o prefeito desinteressado na eleição, não obstante fracassem eleitoralmente. Com isso, minimizamos a chance de que os resultados mostrados nas Tabelas 2 e 3 sejam viesados por causalidade reversa gerada pela possibilidade de que gastos expliquem reeleição, e não o contrário.

$\mathrm{Na}$ segunda coluna da Tabela 5, realizamos teste semelhante, agora entre prefeitos que tentaram reeleição e perderam contra prefeitos em primeiro mandato que não tentaram se reeleger, mas foram seguidos por colega. A teoria prediz que o comportamento de ambos seria semelhante, mas como podemos observar prefeitos em primeiro mandato seguidos por colegas gastam mais do que prefeitos que tentam reeleição e perdem. Novamente, não temos uma medida perfeita de como os prefeitos que não tentam reeleição tentam influenciar o resultado para seu colega de partido, já que captamos somente o caso em que o seu efetivamente foi eleito. Essa limitação pode ser causa da diferença observada. Ou ainda, ao apoiar outro candidato ao invés de disputar a reeleição, o prefeito tenha que gastar mais em saúde para sinalizar competência, uma vez que ele deve transferir o sinal para outra pessoa, o colega de partido. ${ }^{14}$ De todo modo, as duas colunas em conjunto dão corpo à teoria de que motivos reputacionais implicam em mudança no padrão de gastos do político.

\section{CONCLUSÃO}

O artigo tenta encontrar evidências de que a situação eleitoral dos prefeitos influi nas despesas municipais, em particular para a saúde. Utilizamos uma larga amostra de 3.004 municípios brasileiros para testar o modelo de reputação para os anos eleitorais de 2000 e 2004 no setor da saúde.

Os resultados mostram que prefeitos candidatos à reeleição agem estrategicamente para convencer o eleitorado à recondução. Por sua vez, prefeitos em segun-

\footnotetext{
${ }^{14}$ Essa hipótese poderia ser testada confrontando prefeitos em primeiro mandato que não tentam reeleição e são seguidos por colega contra prefeitos em segundo mandato que são seguidos por colegas. De acordo com as hipóteses do modelo, o primeiro caso gastaria mais em saúde em ano eleitoral. Porém, limitações da amostra não permitem este teste. Como para realizar essa estimação devemos excluir da amostra prefeitos que tentaram reeleição e venceram, ao eliminar esses casos para o ano 2000 automaticamente eliminaríamos os municípios com prefeito em segundo mandato de 2004, o único ano em que se observa esse tipo de prefeito. Uma alternativa seria a estimação em Pooled OLS ou em efeito aleatório. As estimativas (ver Apêndice) mostram que de fato prefeitos em primeiro mandato gastam mais em saúde nessa situação. Todavia, como ficou claro ao longo do trabalho, esses métodos reportam estimativas possivelmente viesadas, devido correlação entre as variáveis explicativas e características não observadas constantes no tempo, capturadas pelo teste de Hausman apresentado nas notas de rodapé n. 10 e 11.
} 
do mandato não aumentam as despesas quando encaram o final de seu mandato. Ou seja, o modelo de reputação se encaixa aos municípios brasileiros: prefeitos que tentam reeleição se esforçam, através de maiores gastos em saúde, para mostrar aos seus eleitores que são administradores competentes, ao contrário de prefeitos em segundo mandato.

Encontramos ainda que incentivos partidários parecem ter importante papel na condução da administração municipal. $\mathrm{O}$ modelo de reputação omite qualquer efeito da eleição subsequente ao prefeito que não tenta ou não pode se reeleger. Porém, os resultados sugerem que importa ao prefeito que seu sucessor seja de seu partido.

Testamos o modelo para o tamanho do município e ideologia dos prefeitos, encontrando resultados semelhantes. Além disso, para efeitos de robustez, comparamos prefeitos perdedores contra prefeitos que poderiam, mas não tentaram reeleição. Esse teste indicou que mesmo aqueles prefeitos com menores chances de reeleição se diferenciam do grupo de referência, que é o conjunto dos prefeitos em primeiro mandato que não tentaram reeleição.

\section{REFERÊNCIAS BIBLIOGRÁFICAS}

ANDRADE, M. V. e M. B. LISBOA. (2001). “A economia da saúde no Brasil”. In Menezes-Filho, N. e Lisboa, M. (Org.). Microeconomia e Sociedade no Brasil. Rio de Janeiro, v. 1: 285-330.

BARRO, Robert J. (1973) "The control of politicians: an economic model," Public Choice, 14: $19-42$.

BESLEY, Timothy, e Anne CASE. (1995) "Does electoral accountability affect economic policy choices? Evidence from gubernatorial term limits," The Quarterly Journal of Economics 110 (3): 769-798.

BESLEY, Timothy, e Anne CASE. (2003) "Political institutions and policy choices: Evidence from the United States," Journal of Economic Literature, vol. 41, n. 1: 7-73.

COPPEDGE, Michael. (1997) “A classification of Latin American political parties.” The Hellen Kellog Institute. Working Paper \# 244. November 1997.

FERRAZ, Cláudio, e Frederico FINAN. (2005) "Reelection incentives and political corruption: evidence from Brazilian audit reports." UC Berkeley, mimeo.

LIST, John e Daniel M. STURM. (2006). "How elections matter: Theory and evidence from environmental policy," The Quarterly Journal of Economics, Novembro 2006.

MENEGUIN, Fernando B. e Maurício BUGARIN. (2001) "Reeleição e política: Um estudo dos efeitos da reeleição nos gastos públicos," Economia Aplicada, ver. 5, n. 3: 600-22.

NISHIJIMA, M., G. BIASOTO Junior e D. CYRILLO. (2006) “Análise econômica da interação entre saúde pública e privada no Brasil: tratamentos de alta complexidade”. In Encontro Nacional de Economia, 2004, Salvador. Anais do XXXII Encontro Nacional de Economia.

PEREIRA, Carlos e Lúcio RENNÓ. (2007) "O que é que o reeleito tem? O retorno: o esboço de uma teoria da reeleição no Brasil," Revista de Economia Política, vol. 27, n. 4, Out-Dez.

PERSON, Torsten, e Guido TABELLINI. (2000) Political Economics: Explaining Economic Policy. Cambridge, Massachussets: MIT Press.

ROGOFF, Kenneth e Anne SIBERT. (1988) "Elections and macroeconomic policy cycles," The Review of Economic Studies, vol. 55, n. 1: 1-16.

ROGOFF, Kenneth. (1990) Equilibrium political budget cycles The American Economic Review, vol. 80, n. $1: 21-36$. 
SMART, Michael e Daniel STURM. (2006) “Term limits and electoral accountability” CEP Discussion Paper n. 770.

TEIXEIRA, Luciana; Maurício BUGARIN e Maria Cristina DOURADO. (2006) "Intermunicipal health care consortia in Brazil: strategic behavior, incentives and sustainability", The International Journal of Health Planning and Management, vol. 21: 275-296.

VEIGA, Linda G. e Francisco J. VEIGA. (2007) "Political business cycles at the municipal level," Public Choice, 131: 45-64

WOOLDRIDGE, Jeffrey. (2002) Econometric analysis of cross section and panel data. Cambridge, MA: MIT Press.

\section{APÊNDICE}

$\mathrm{Na}$ tabela a seguir confrontamos os dois grupos de prefeitos que foram seguidos por colegas de partido: prefeitos que não tentaram a reeleição e prefeitos em segundo mandato. Conforme podemos observar, prefeitos em segundo mandato gastam menos em saúde do que o grupo de referência, composto por prefeitos em primeiro mandato que não tentaram a reeleição, mas foram seguidos de colega de partido. Porém, estas estimativas possivelmente estão viesadas (ver nota de rodapé n. 13).

Tabela 6: Análise de robustez: prefeitos seguidos por colegas de partido

\begin{tabular}{|c|c|c|}
\hline \multicolumn{3}{|c|}{ Variável dependente: LNSUS } \\
\hline & \multicolumn{2}{|c|}{ Estimação } \\
\hline & Pooled OLS & Efeito Aleatório \\
\hline & -0.0766 & -0.0708 \\
\hline \multirow{2}{*}{$\begin{array}{l}\text { Prefeitos em segundo mandato } \\
\text { seguidos por colega de partido }\end{array}$} & {$[0.0437]$} & [0.0433] \\
\hline & (0.08) & $(0.102)$ \\
\hline Controles políticos & Sim & Sim \\
\hline Controles saúde & Sim & Sim \\
\hline Controles município & Sim & Sim \\
\hline Ideologia & Sim & Sim \\
\hline N. obs. & 721 & 721 \\
\hline Prob $>F, W$ & 26.7100 & 0.0000 \\
\hline $\mathrm{R} 2$ & 0.5361 & 0.5358 \\
\hline
\end{tabular}

Obs.: Erro padrão robusto entre colchetes e p-valor entre parênteses. Todas as estimações incluem intercepto, dummies para Unidades de Federação e dummy de ano. Controles políticos: LEGISLAT, VOTMAJ, PARTPRES e PARTGOV. Controles saúde: SUPLEM, LNSUS, MORT. Controles município: AGUA, ESGOTO, RENDA, POPULAÇÃO, URBAN, JOVENS. Ideologia: DIREITA, ESQUERDA. 